\title{
Mental Health Effects of COVID-19 Pandemia: A Review of Clinical and Psychological Traits
}

\author{
Konstantinos Kontoangelos ${ }^{1,2} \bowtie$, Marina Economou ${ }^{1,2}$, and Charalambos Papageorgiou ${ }^{1,2}$ \\ ${ }_{11}$ st Department of Psychiatry, Eginition Hospital, Medical School National \& Kapodistrian University of Athens, Athens, Greece \\ ${ }^{2}$ University Mental Health Research Institute, Athens, Greece
}

\begin{abstract}
Objective As the coronavirus (COVID-19) pandemic sweeps across the world, it is causing widespread concern, fear and stress, all of which are natural and normal reactions to the changing and uncertain situation that everyone finds themselves in.

Methods In this general review, we examined the literature about the psychological effects of COVID-19 pandemia. In total 65 papers were reviewed using the Medline computer database. Only publications in English were selected.

Results Children are likely to be experiencing worry, anxiety and fear and older people are also those with underlying health conditions, having been identified as more vulnerable to COVID-19, can be extremely frightening and very fear-inducing. China and several other countries took strict isolation measures. Medical staff and affiliated healthcare workers (staff) are under both physical and psychological pressure.

Conclusion The COVID-19 pandemic is exceptional. Its effect will likely be imprinted on each individual involved. Extensive stressors will emerge or become worsened. Many medical staff workers will be harmfully psychologically affected. Psychiatry Investig 2020;17(6):491-505
\end{abstract}

Key Words COVID-19, Psychiatry, Pandemia, Mental health, Public crisis.

\section{INTRODUCTION}

In January 2020 the World Health Organization (WHO) declared the outbreak of a new coronavirus disease, COVID-19, to be a Public Health Emergency of International Concern. WHO stated that there is a high risk of COVID-19 spreading to other countries around the world. In March 2020, WHO made the assessment that COVID-19 can be characterized as a pandemic. WHO and public health authorities around the world are acting to contain the COVID-19 outbreak. ${ }^{1}$ However, this time of crisis is generating stress throughout the population. The considerations presented in this document have been developed by the WHO Department of Mental Health and Substance Use as a series of messages that can be used in communications to support mental and psychosocial well-being in different target groups during the outbreak. ${ }^{2}$ COVID-19 pan-

Received: May 11, 2020 Accepted: May 24, 2020

$\triangle$ Correspondence: Konstantinos Kontoangelos, MD, PhD

1st Department of Psychiatry, Eginition Hospital, Medical School National \& Kapodistrian University of Athens, 74 Vas Sofias Avenue, 11528, Athens, Greece Tel: +0030-210-7289409, Fax: +0030-210-7242020

E-mail: kontoangel@med.uoa.gr

(a) This is an Open Access article distributed under the terms of the Creative Commons Attribution Non-Commercial License (https://creativecommons.org/licenses/bync/4.0) which permits unrestricted non-commercial use, distribution, and reproduction in any medium, provided the original work is properly cited. demic not only affects physical health, but also mental health and well-being. The current pandemic is changing priorities for the general population, but it is also challenging the agenda of health professionals, including that of psychiatrists and other mental health professionals. ${ }^{3}$ Everywhere in the world, psychiatric clinics are modifying their practice in order to guarantee care and support to persons with mental health problems, but also to those who are not mentally ill and are suffering from the psychosocial consequences of the pandemic. The number of those who will need psychiatric help is going to increase in the next weeks or months, requiring a reconsideration of our current practices. From a psychopathological viewpoint, the current pandemic is a relatively new form of stressor or trauma for mental health professionals. ${ }^{4}$ COVID-19, the infection caused by the novel coronavirus detected in December 2019, raising concerns of widespread panic and increasing anxiety and although the effects of the coronavirus on mental health have not been systematically studied, it is anticipated that COVID-19 will have rippling effects, especially based on current public reactions.

\section{METHODS}

This paper aims to review of the latest papers referring to 
the psychiatric and psychological effects of pandemia in the general population. The literature search was done using the Medline computer database. It focused in all studies concerning COVID-19 pandemia and psychiatry. The keywords were selected from titles, abstract and keywords and they were the following "COVID-19" "psychiatry" and "mental health." Only publications in English were selected.

\section{RESULTS}

\section{Psychological approaches}

The coronavirus disease 2019 (COVID-19) pandemic it will cause an extraordinary stressor to patients and health care systems across the globe and people with serious mental illnesses should be provided truthful information about strategies related with the medical treatment for COVID-19. It will also be important to deal with the psychological and social dimensions of this epidemic for patients. Worry could both exacerbate and be exacerbated by existing anxiety and depressive symptoms. ${ }^{5}$ Psychiatrists can play essential role in supporting the well-being of those affected and their families and crucial interventions can be related with the education about the common adverse psychological costs and encouraging health-promoting behaviours, the facilitation of problem solving and finally the empowerment of the patients, their families and health-care providers. ${ }^{6}$ Existing focus on the global transmission of COVID-19 infection might distract public attention from psychosocial cost of the outbreak in the affected individuals and in the general population. The emerging mental health issues related to this epidemic event may develop into long-lasting health problems, isolation and stigma. Global health measures should be employed to address psychosocial stressors, particularly related to the use of isolation/quarantine, fear and vulnerability among the general population. The information from media and social network should be closely controlled and community supportive psychological interventions globally promoted. ${ }^{7}$ Still the most important thing we can do is minimize the transmission of the virus through disciplined hygiene and social distancing. The fewer people who get infected in the general population, the lower the risk of infection for long-term care residents. ${ }^{8}$ Mental health problems associated with the COVID-19 pandemic include high rates of psychiatric symptoms, and mental health considerations are highly relevant because mental health disorders (e.g., depression, anxiety disorders, posttraumatic stress disorder and substance use disorders) are common in patients with chronic pain. Mental health problems associated with the COVID-19 pandemic could exacerbate these pre-existing conditions which, in turn, could adversely impact pain-related treatment outcomes. ${ }^{9}$ If a patient with psychiatric disorders infected with the COVID-19, antiviral drugs must be used in combination with psychotropic drugs, including antipsychotic, antidepressant, and anti anxiety drugs. If antiviral drugs are used without supplemental medication, patients with psychiatric disorders can experience relapses in their mental illness. ${ }^{10}$ From a pharmacological point of view Siskind et al. ${ }^{11}$ focus on specific recommendations correlated with the prescription of clozapine. With the ongoing coronavirus disease (COVID-19) pandemic, psychiatrists find themselves in the clinical situation of being asked by patients, family members and patient advocacy societies to help ensure access to clozapine as a medication critical for ongoing patient care. Clozapine may be associated with a higher risk of pneumonia, likely due to sialorrhea and aspiration rather than neutropenia. Clozapine levels can increase with acute systemic infection, leading to symptoms of acute clozapine toxicity, including sedation, myoclonus and seizures. Despite similarities with previous pandemics and a rapid response by the scientific community to understand COVID-19 and reduce its global impact, there is still much that we do not know, especially given the novel features of COVID-19, and governments varying responses to the crisis worldwide. There is therefore an urgent need for health psychology research and a need to understand the potential physical and psychosocial impact of COVID-19 on front-line health care staff. ${ }^{12}$ There are many reasons for this. It is known that psychological factors play an important role in adherence to public health measures (such as vaccination) and in how people cope with the threat of infection and consequent losses. These are clearly crucial issues to consider in the management of any infectious disease, including COVID-19. Psychological reactions to pandemics include maladaptive behaviours, emotional distress and defensive responses. People who are prone to psychological problems are especially vulnerable. ${ }^{13}$ An online assessment was incorporated to examine the pattern of posttraumatic stress symptoms in clinically stable COVID-19 patients. A total of 730 COVID-19 patients were recruited in this study, of whom, 714 met the inclusion criteria. The mean age of the participants $50.2 \pm 12.9$ years, men accounted for $49.1 \%$ of the sample, and $25.8 \%$ lived alone prior to admission. The prevalence of significant posttraumatic stress symptoms was 96.2\% (95\%CI: 94.8-97.6\%). Half of participants (49.8\%) considered psycho-educational services helpful. ${ }^{14}$ The rapid transmission rates of COVID-19 alongside with demeaning news coverage in widely used communication programs, and social discrimination towards COVID-19 patients may result in higher prevalence of self-perceived posttraumatic stress symptoms. ${ }^{15}$ Health anxiety occurs when perceived bodily sensations or changes, including but not limited to those related to infectious diseases (e.g., fever, coughing, aching muscles), are interpreted as symptoms of being ill. There are several ways in which high health anxiety may influence behavioural responses to the belief of being infected. On the one hand, some people 
Table 1. Characteristics of 19 studies reporting psychological parameters

\begin{tabular}{|c|c|c|c|c|}
\hline Region of university & Author & $\begin{array}{c}\text { Year of } \\
\text { publication }\end{array}$ & Type of paper & $\begin{array}{l}\text { Sample } \\
\text { size }\end{array}$ \\
\hline $\begin{array}{l}\text { Rollins School of Public Health, Emory University, Atlanta, } \\
\text { Georgia, USA }\end{array}$ & Druss BG & 2020 & Viewpoint & 0 \\
\hline $\begin{array}{l}\text { Department of Psychiatry, National Institute of Mental Health and } \\
\text { Neurosciences (NIMHANS), Hosur Road, Bangalore 560029, India }\end{array}$ & Banerjee D & 2020 & Letter & 0 \\
\hline $\begin{array}{l}\text { Department of Psychiatry, School of Medical Sciences, National } \\
\text { University of Asunción, Asunción, Paraguay }\end{array}$ & Torales J & 2020 & Review & 0 \\
\hline $\begin{array}{l}\text { School of Epidemiology and Public Health, Child and Adolescent } \\
\text { Psychiatry, University of Ottawa, Ottawa, Ontario, Canada }\end{array}$ & Gardner W & 2020 & Viewpoint & 0 \\
\hline $\begin{array}{l}\text { Neurology and Physical Medicine and Rehabilitation and Chief of } \\
\text { Pain Medicine, Johns Hopkins School of Medicine, USA }\end{array}$ & Cohen S & 2020 & $\begin{array}{l}\text { Recommendation } \\
\text { and guidelines }\end{array}$ & 0 \\
\hline $\begin{array}{l}\text { Department of Psychiatry, Chaohu Hospital, Anhui Medical University, } \\
\text { Hefei, Anhui, China }\end{array}$ & Kai Zhang & 2020 & Letter & 0 \\
\hline Metro South Addiction and Mental Health Service, Brisbane, Australia & Dan Siskind & 2020 & $\begin{array}{l}\text { Paper for clinician with } \\
\text { recommendations }\end{array}$ & 0 \\
\hline $\begin{array}{l}\text { Centre for Behavioural Science and Applied Psychology, } \\
\text { Sheffield Hallam University, UK }\end{array}$ & Arden MA & 2020 & Letter & 0 \\
\hline School of Medicine, University College Dublin, Belfield, Dublin, Ireland & Cullen W & 2020 & Comment & 0 \\
\hline $\begin{array}{l}\text { Department of Nursing, Peking Union Medical College Hospital, } \\
\text { Beijing, China }\end{array}$ & Bo HX & 2020 & Research paper & 734 \\
\hline Department of Sociology and Anthropology, Concordia University, Canada & Monson E & 2017 & Research paper & 2,433 \\
\hline Department of Psychology, University of Regina, Canada & Asmundson GJG & 2020 & Editorial & 0 \\
\hline St George's University of London, UK & Ahmad A & 2020 & Letter & 0 \\
\hline
\end{tabular}

with high health anxiety may regard hospitals and doctor's offices as a source of contagion and, therefore, avoid seeking medical assistance. On the other hand, other people with high health anxiety tend to seek out health-related information and reassurance, often from doctors. As such, they may visit multiple doctors or even attend hospital emergency rooms in their pursuit of reassurance that their bodily sensations and changes are not due to infection. ${ }^{16}$ The fear of $2019-\mathrm{nCoV}$ is likely due to its novelty and the uncertainties about how bad the current outbreak might become. Fear of 2019-nCoV is much greater than fear of seasonal influenza, even though the latter has killed considerably more people. According to the Morning Consult (2020) poll, $37 \%$ of Americans were very concerned about 2019-nCoV whereas $27 \%$ were very concerned about seasonal influenza, and most respondents (62\%) were more worried about 2019$\mathrm{nCoV}$ than they were about seasonal influenza. While the nature and impact of 2019-nCoV on mental health remains to be determined, there are clues in the existing literature that may help us begin to understand what to expect. Research on the psychological reactions to previous epidemics and pandemics suggests that various psychological vulnerability factors may play a role in coronaphobia, including individual difference variables such as the intolerance of uncertainty, perceived vul- nerability to disease, and anxiety. ${ }^{17}$ During epidemics, the number of people whose mental health is affected tends to be greater than the number of people affected by the infection. Patients infected with COVID-19 (or suspected of being infected) may experience intense emotional and behavioral reactions, such as fear, boredom, loneliness, anxiety, insomnia or anger. It is extremely necessary to implement public mental health policies in combination with epidemic and pandemic response strategies before, during and after the event. Mental health professionals, such as psychologists, psychiatrists and social workers, must be on the front line and play a leading role in emergency planning and management teams. ${ }^{18}$ Given the humanitarian challenges of the ongoing pandemic, we think that COVID-19 needs a public mental health focus. COVID-19 is the first major pandemic of our generation, and we must seek the hidden opportunities to reflect and react as a global society. COVID-19 is as much a challenge of how we are going to frame it from a psychiatric perspective as it is a public health crisis. By merging public health with mental health, the ways that COVID-19 are changing the world could be for better rather than worse (Table 1). ${ }^{19}$ 
Table 2. Publications related with the psychiatric management of the elderly

\begin{tabular}{lccc}
\hline \multicolumn{1}{c}{ Region of university } & Author & $\begin{array}{c}\text { Year of } \\
\text { publication }\end{array}$ & $\begin{array}{c}\text { Type of paper } \\
\text { Sample } \\
\text { size }\end{array}$ \\
\hline $\begin{array}{l}\text { Dementia Care and Research Center, Peking University Institute of Mental Health } \\
\text { (Sixth Hospital), Beijing Dementia Key Lab, Beijing 100191, China }\end{array}$ & Wang H & 2020 & Correspondence \\
0 \\
$\begin{array}{l}\text { Unit of Psychiatry, Institute of Translational Medicine, Faculty of Health Sciences, } \\
\text { Universit of Macau, China }\end{array}$ & Yang Y & 2020 & Correspondence \\
\hline
\end{tabular}

\section{Psychiatric management of the elderly during the pandemia}

Older adults are vulnerable at the onset of natural disasters and crisis, and especially those suffering from dementia have limited access to accurate information and facts about the COVID-19 pandemic. They might have difficulties in remembering safeguard procedures, such as wearing masks, or in understanding the public health information. Mental health professionals, social workers, nursing home administrators, and volunteers should deliver mental health care for people living with dementia. Vigilance about the health of the elderly in long-term care is essential not only for their health but also to protect the health care system from being overwhelmed by severe COVID-19 cases. ${ }^{20}$ Mental health problems are common in older Chinese adults (i.e., $\geq 55$ years), with the prevalence of depressive symptoms reported to be $23.6 \%$ in this population. The rapid transmission of the severe acute respiratory syndrome corona virus (SARS$\mathrm{CoV}-2$ ) and high death rate could exacerbate the risk of mental health problems and worsen existing psychiatric symptoms, further impairing their daily functioning and cognition. Stakeholders and health policy makers should collaborate to resolve this barrier in order to provide high-quality, timely crisis psychological services to community-dwelling older adults (Table 2). ${ }^{21}$

\section{Psychological effects of Pandemia in children}

A particular scientific interest is related with children's normal psychological development and wellbeing. Separation from caregivers might increase the risk of psychiatric disorders. Children who were isolated or quarantined during pandemic diseases were more likely to develop acute stress disorder, adjustment disorder, and grief $30 \%$ of the children who were isolated or quarantined met the clinical criteria for posttraumatic stress disorder. ${ }^{22}$ Children are experiencing substantial changes to their daily routine and social infrastructure, because of COVID-19 pandemic and the information provided needs to take into account the child's age and level of understanding. Sensitive and effective communication about life-threatening illness has major benefits for children and their family's long-term psychological wellbeing. Ignor- ing the immediate and long-term psychological effects of this global situation would be unconscionable, especially for children and young people, who account for $42 \%$ of our world's population. ${ }^{23}$ Another critical issue during this pandemic is that in this situation the handling of young children with special needs such as autism spectrum condition (ASC) could be challenging for families and caregivers. Usually these children have interventions for several hours a week at home with special therapists or in dedicated hospitals and institutes. Parents and Caregivers of Young Children with ASC can be helped handle the children by explaining in the children what COVID-19 is, by the use of serious games, by online therapy for high-functioning children and by weekly online consultations for parents and caregivers. ${ }^{24}$ Coronavirus disease 2019 (COVID-19) is changing family life. Parents and caregivers are attempting to work remotely or unable to work, while caring for children, with no clarity on how long the situation will last. Violence and vulnerability increase for children during periods of school closures associated with health emergencies. Rates of reported child abuse rise during school closures. Parents and children are living with increased stress, media hype, and fear, all challenging our capacity for tolerance and longterm thinking. For many, the economic impact of the crisis increases parenting stress, abuse, and violence against children (Table 3$)^{25}$

\section{Psychosocial effects of pandemia in China}

The novel coronavirus (COVID-2019) has spread very rapidly all over China and several other countries took strict isolation measures and delays in starting schools, colleges, and universities across the country. Public health emergencies can have many psychological effects on college students, which can be expressed as anxiety, fear, and worry, among others. About $24.9 \%$ of college students have experienced anxiety because of this COVID-19 outbreak. Living in urban areas, living with parents, having a steady family income were protective factors for college students against experienced anxiety during the COVID-19 outbreak. However, having a relative or an acquaintance infected with COVID-19 was an independent risk factor for experienced anxiety. ${ }^{26}$ From a medical and psychical approach, stress can be related with severe acute respiratory 
Table 3. Publication related with the psychological effects of pandemia in children

\begin{tabular}{lccc}
\hline \multicolumn{1}{c}{ Region of university } & Author & $\begin{array}{c}\text { Year of } \\
\text { publication }\end{array}$ & $\begin{array}{c}\text { Type of paper } \\
\text { Sample } \\
\text { size }\end{array}$ \\
\hline $\begin{array}{l}\text { Peking University Health Science Center, Peking University, } \\
\text { Beijing 100191, China }\end{array}$ & Liu JJ & 2020 & Comment \\
$\begin{array}{l}\text { Department of Psychiatry, University of Oxford, Oxford OX3 7JX, UK } \\
\text { Department of Child Psychiatry and Psychopharmacology, IRCCS Stella Maris }\end{array}$ & Dalton L & 2020 & Comment \\
$\begin{array}{l}\text { Foundation, 56018 Pisa, Italy } \\
\text { Department of Social Policy and Intervention, University of Oxford, Oxford OX1 }\end{array}$ & Cluver L & 2020 & Editorial \\
2ER, UK; Department of Psychiatry and Mental Health, University of & & & Correspondence \\
Cape Town, Cape Town, South Africa & & & 0 \\
\hline
\end{tabular}

syndrome coronavirus (SARS-CoV) and critical cardiac lesions. ${ }^{27}$ The COVID-19 epidemic in China has ignited another epidemic of stress, anxiety and depression. Since the outbreak of COVID-19, the Chinese government has taken proactive measures to contain not only the spread of the novel coronavirus but also that of psychological distress in the public. There is intense concern about the provision of online mental health services, with the utilization of these services to a large extent neglected and individuals with lower socioeconomic status (SES) might not have as much access to digital technologies. ${ }^{28}$ In the current home confinement situation due to the COVID-19 outbreak, most individuals are exposed to an unprecedented stressful situation of unknown duration. This may not only increase daytime stress, anxiety and depression levels but also disrupt sleep. Importantly, because of the fundamental role that sleep plays in emotion regulation, sleep disturbance can have direct consequences upon next day emotional functioning. People need adaptions of cognitive behavioral therapy elements that are feasible to implement for those facing changed work schedules and requirements, those with health anxiety and those handling childcare and homeschooling, whilst also recognizing the general limitations imposed on physical exercise and social interaction. Managing sleep problems as best as possible during home confinement can limit stress and possibly prevent disruptions of social relationships. ${ }^{29}$ First-line medical workers and scientists played a leading role in fighting against the COVID-19 outbreak. China sent many medical works from across the country to Hubei province in the virus fight. Mental health care for the frontline medical workers around the word is urgently needed. The frontline medical professionals worked under great psychological stress and faced many challenges and losses. The large number of COVID-19 patients, suspected cases, hospitalizations, and patients in critical condition made the medical work incredibly hard. The transmission of COVID-19 from human-to-human and the increasing number of deaths could elicit their fear about being infected. The bad outcomes of some critical pa- tients, the suffering of patients and their relatives could lead to worsening anxiety and mental distress. ${ }^{30}$ In China to explore the mental health status of medical and nursing staff and the efficacy, or lack of critically connecting psychological needs to receiving psychological care, researchers conducted a quantitative study. Notably, among 994 medical and nursing staff working in Wuhan, 36.9\% had subthreshold mental health disturbances, $34.4 \%$ had mild disturbances, $22.4 \%$ had moderate disturbances, and $6.2 \%$ had severe disturbance in the immediate wake of the viral epidemic. The noted burden fell particularly heavily on young women. Of all participants, 36.3\% had accessed psychological materials (such as books on mental health), 50.4\% had accessed psychological resources available through media (such as online push messages on mental health self help coping methods), and $17.5 \%$ had participated in counseling or psychotherapy. Trends in levels of psychological distress and factors such as exposure to infected people and psychological assistance were identified. ${ }^{31}$ The prevalence of posttraumatic stress symptoms (PTSS) in China hardest-hit areas a month after the COVID-19 outbreak was 7\% and women reported significant higher PTSS in the domains of re-experiencing, negative alterations in cognition or mood, and hyperarousal. ${ }^{32}$ In China a key recommendation is to shift services from institutions to the community, highlighting the steps required to provide appropriate psychiatric services for patients in the current epidemic of COVID-19. Apart from this, with the development of artificial intelligence techniques in clinical settings, attempts to speed up constructing the framework of online consultation and internet hospitals, as well as carrying out telemedicine, are valuable. As one the fundamental components of mental health service, the large top-class tertiary hospitals-based psychiatric health care professionals are easy to play critical roles in comprehensive health of population with mental disorders. This can be leveraged through big data analyses and harnessed via updated clinical practice guidelines and algorithms to improve policy-making. ${ }^{33}$ In order to reduce the risk of developing mental health problems, simple advices may 
be provided to the general population 1) limit the sources of stress, 2) break the isolation, 3) maintain your usual rhythm, 4) focus on the benefit of the isolation, 5) ask for professional help. The vulnerability to psychological distress across populations in the COVID-19 pandemic could be attributable to various factors, including gender, social support, specific experiences with COVID-19 infection, length of isolation, and amount of exposure to the media. ${ }^{34}$ In a study about the attitudes, and practices towards COVID-19 among Chinese residents during the rapid rise period of the COVID-19 outbreak the results showed that the majority of the respondents (97.1\%) had confidence that China can win the battle against COVID-19. Nearly all of the participants (98.0\%) wore masks when going out in recent days. In multiple logistic regression analyses, the COVID-19 knowledge score was significantly associated with a lower likelihood of negative attitudes and preventive practices towards COVID-2019. Most Chinese residents of a relatively high socioeconomic status, in particular women, are knowledgeable about COVID-19, hold optimistic attitudes, and have appropriate practices towards COVID-19. Health education programs aimed at improving COVID-19 knowledge are helpful for Chinese residents to hold optimistic attitudes and maintain appropriate practices. ${ }^{35}$ One of the largest community mental health projects globally is the mental health care model in China entitled the "Management and treatment program for severe mental illness." In order to establish community-based mental health services nationwide, this project integrated the resources in psychiatric hospitals and existing community psychiatric services and trained mental health professionals in the development of individual service plans. The COVID-19 outbreak has raised numerous challenges for psychiatric hospitals in China to safely manage patients' major psychiatric disorders in addition to preventing and treating COVID-19. In addressing these challenges, future community mental health system reform is necessary to re-balance the system by re-distributing resources from hospital-centric services to community-based and primary care services. ${ }^{36}$ In recent years, Chinese health workers are often confronted with frustrating situations in the health care system including serious workplace violence against clinicians. A meta-analysis found that the overall prevalence of workplace violence was $62.4 \%$ among Chinese health workers. Regardless of the unsafe clinical environment, Chinese health workers are always committed to provide timely health services without any hesitation or reservations. For instance, as of February 12, 2020, a total of 189 external expert teams comprising 21,569 health workers from other regions of China have volunteered to work in $\mathrm{Hu}$ bei province, disregarding the high risk of contracting the infection and the high mortality rate of the COVID-19 among health workers. ${ }^{37}$ Despite the Chinese authorities have an- nounced relevant policies and actuating principles in a strategic manner, the COVID-19 outbreak has posted an emerging serious challenge for the mental health services in China. There are some limitations that need to be addressed. First, several online mental health services have been constructed across different areas, however, unified national management and coordination policies are still inadequate, which could result in uneven distribution and wastage of medical resources, let alone evaluating the efficacy of these services. Second, online mental health services are the predominant assistance measure and therefore, some people (e.g., older adults) who may have limited access to smartphones and the broadband internet, may benefit less from the services. Third, frontline health professionals may have limited time and energy to access to these services due to heavy workload. Fourth, based on experiences of SARS outbreak, some patients and health professionals would be traumatized by the COVID-2019 outbreak and still suffer from persistent psychiatric symptoms even after the outbreak. ${ }^{38}$ In a cross-sectional survey that enrolled 1,257 respondents the results revealed a high prevalence of mental health symptoms among health care workers treating patients with COVID-19 in China. Overall, 50.4\%, 44.6\%, 34.0\%, and $71.5 \%$ of all participants reported symptoms of depression, anxiety, insomnia, and distress, respectively. Participants were divided in 3 groups (Wuhan, other regions in Hubei province, and regions outside Wuhan province) to compare interregional differences. Most participants were female, were nurses, were aged 26 to 40 years, were married, and worked in tertiary hospitals with a junior technical title. Nurses, women, those working in Wuhan, and frontline workers reported more severe symptoms on all measurements. The same study further indicated that being a woman and having an intermediate technical title were associated with experiencing severe depression, anxiety, and distress. ${ }^{39}$ Surveying more than 1,200 nurses and physicians in 34 hospitals in the Wuhan region and across mainland China, the authors found striking prevalence rates of symptoms of depression and anxiety; half of those responding identified at least mild depression on a validated screening instrument, and one-third reported insomnia. Approximately $14 \%$ of physicians and nearly $16 \%$ of nurses described moderate or severe depressive symptoms. Those at greatest risk for depressive and anxious symptoms included women, those with intermediate seniority titles (compared with those with junior roles), and those at the center of the epidemic in $\mathrm{Wu}$ han. ${ }^{40}$ Another phenomenon of pandemia is that many countries in which numerous Chinese students pursue their academic studies announced travel restrictions on foreign nationals to contain COVID-19. International Chinese students are living with the fear that their families in China are susceptible and at risk of infection with severe acute respiratory 
syndrome coronavirus 2 (SARS-CoV-2), responsible for COVID-19. They also face discrimination and isolation in some countries due to being deemed as potential SARS-CoV-2 carriers. Some media outlets have used derogatory headlines, perpetuating stereotypes and prejudices about Chinese people. ${ }^{41}$ In China, 173 million people are living with mental health disorders, and neglect and stigma regarding these conditions still prevail in society. When epidemics arise, people with mental health disorders are generally more susceptible to infections for several reasons. Mental health disorders can increase the risk of infections, including pneumonia and once infected with severe acute respiratory syndrome coronavirus which results in COVID-19 people with mental disorders can be exposed to more barriers in accessing timely health services, because of discrimination associated with mental ill-health in health-care settings. ${ }^{42}$ With the progress of the disease in China, clinical symptoms become severe and psychological problems in infected patients will change; therefore, psychological intervention measures should be targeted and adapted as appropriate. Interventions should be based on a comprehensive assessment of risk factors leading to psychological issues, including poor mental health before a crisis, bereavement, injury to self or family members, life threatening circumstances, panic, separation from family and low household income (Table 4$){ }^{43}$

\section{Psychiatric consequences of pandemia in other countries}

In Italy, about the $25 \%$ of the overall burden of disease is attributed to neuropsychiatric disorders. The community-based Italian psychiatric assistance is integrated in the National Health System, includes 183 Mental Health Departments and takes care almost 780,000 patients. Currently, patients are continuously followed-up, mainly with the use of internet connections. However, the actual stressful period and social isolation may increase the risk of recurrence and new episodes. In fact, people are forced now to live isolated because social distancing is the most effective strategy to limit the spread of the virus. However, social isolation, especially if protracted, may increase the risk of mental disorders such as anxiety, mood, addictive and thought disorders. ${ }^{44}$ In USA, the crisis has highlighted the extent of interconnectedness of their institutions, including medical, public health, political, economic, and educational. The current pandemic clearly underscores the global nature of their lives today and the limited constructs of nationality, religion, and political leanings in the face of a common threat. They cannot fully anticipate the long-lasting effects of this pandemic on our societies. There they have seen telemedicine set up at record speed to meet the needs of patients. Regulatory barriers to reach many patients were brought down almost overnight. They can use more platforms and cross state lines to deliver care, which are important changes that help us reach as many patients as possible. They are collectively experiencing a stressor that affects segments of the population in different ways. ${ }^{45}$ In Japan, economic impacts and social disruptions have been reported. This is not the first time for the Japanese people to experience imperceptible agent emergencies-often dubbed as CBRNE (chemical, biological, radiological, nuclear, and high-yield explosives). In 1945, two atomic bombings took place; the sarin gas attacks in 1995, H1N1 influenza pandemic in 2009, and the Fukushima nuclear accident in 2011 all carried fear and risk associated with unseen agents. These events provoked social disruptions. Overwhelming and sensational news headlines and images added anxiety and fear to these situations as well as fostered rumors and hyped information as individuals filled in the absence of information with rumors. The affected people were subject to societal rejection, discrimination, and stigmatization (Table 5). ${ }^{46}$

\section{The heroic efforts of the health care workers during COVID-19 pandemia}

During a pandemic, the demands on healthcare staff are extraordinary and work-related stress disproportionally affects healthcare workers and is linked to excessive workloads working in emotionally charged environments and may increase patient safety incidents, medical errors, lower quality service provision, along with issues regarding staff retention and psychological ill-health follow. ${ }^{47}$ For example, ECT practitioners need to liaise with their senior anaesthetic colleagues to optimise a safe environment for ECT and determine the most appropriate PPE to be used. The COVID pandemic is a rapidly evolving situation and ECT practitioners need to keep abreast of developments and changing policies. Regularly updated information and clinical guidance should be accessed from reputable national and international scientific and medical organisations, e.g., the Health Service Executive in Ireland. ${ }^{48}$

Front-line key workers, such as healthcare providers and emergency first responders but also other non-healthcare related staff (e.g., social workers, prison staff), may be especially vulnerable to experiencing moral injuries during this time. Recommendations for clinicians providing psychological support during and after the COVID-19 Pandemic include: Psychological support for those in front-line roles and affected by the COVID-19 and clinicians should also be aware that individuals who develop moral injury-related mental health disorders are often reticent to speak about guilt or shame and may instead focus on more classically traumatic elements of their presentation. Clinicians offering psychological treatment to patients should continue to do so, taking precautionary measures where needed- such as offering treatment via 
Skype, Zoom, telephone or similar. Steps should be taken by clinical care teams to ensure that vulnerable groups, such as survivors of domestic violence, and those with serious mental illnesses continue to be able to access treatment and support networks. ${ }^{49}$ Comprehensive survey about the psychological effect of the COVID-19 outbreak on hospital staff of different ranks and positions is needed to provide timely and appropriate interventions. Enhancing the psychological wellbeing of hospital staff during the COVID-19 outbreak is equally important to the fight against the outbreak..$^{50}$ During the current COVID-19 disease emergency, it is not only an ethical imperative but also a public health responsibility to keep the network of community psychiatry services operational, particularly for the most vulnerable ones (subjects

Table 4. Publications related with the psychosocial effects of pandemia in China

\begin{tabular}{|c|c|c|c|c|}
\hline Region of university & Author & $\begin{array}{c}\text { Year of } \\
\text { publication }\end{array}$ & Type of paper & $\begin{array}{l}\text { Sample } \\
\text { size }\end{array}$ \\
\hline Department of Psychology, University of Regina, Canada & Asmundson GJG & 2020 & Editorial & 0 \\
\hline $\begin{array}{l}\text { Centro de Pesquisa em Álcool e Drogas, Hospital de Clínicas de } \\
\text { Porto Alegre, Universidade Federal do Rio Grande do Sul, } \\
\text { Porto Alegre, RS, Brazil }\end{array}$ & Ornell F & 2020 & $\begin{array}{l}\text { Article with } \\
\text { recommendations } \\
\text { about health strategies }\end{array}$ & 0 \\
\hline Harvard T.H. Chan School of Public Health, Boston, MA, USA & Yao $\mathrm{H}$ & 2020 & Letter to the Editor & 0 \\
\hline Beijing Anding Hospital, Capital Medical University, Beijing, China & Xiang YT & 2018 & Research paper & 0 \\
\hline $\begin{array}{l}\text { Psychiatry Department and Mental Health Institute of the Second } \\
\text { Xiangya Hospital, Central South University; China National } \\
\text { Clinical Research Center on Mental Disorders; China National } \\
\text { Technology Institute on Mental Disorders; Hunan Key Laboratory } \\
\text { of Psychiatry and Mental Health, Changsha, Hunan, China }\end{array}$ & Huang J & 2020 & Letter to the Editor & 0 \\
\hline $\begin{array}{l}\text { Department of Psychiatry, Renmin Hospital of Wuhan University, } \\
\text { Wuhan 430060, China }\end{array}$ & Kang L & 2020 & Research paper & 994 \\
\hline $\begin{array}{l}\text { Lab for Post-traumatic Stress Disorder, Faculty of Psychology and } \\
\text { Mental Health, Naval Medical University, Shanghai 200433, China; } \\
\text { The Emotion \& Cognition Lab, Faculty of Psychology and Mental } \\
\text { Health, Naval Medical University, Shanghai 200433, China }\end{array}$ & Liu $\mathrm{N}$ & 2020 & Research paper & 300 \\
\hline $\begin{array}{l}\text { Department of Clinical Psychology, Fourth Military Medical } \\
\text { University, Xian, China }\end{array}$ & Cui LB & 2020 & Letter to the Editor & 0 \\
\hline $\begin{array}{l}\text { Department of Psychiatry, The Third People's Hospital of } \\
\text { Zhongshan, Guangdong 528451, China }\end{array}$ & Zhang J & 2020 & Research paper & 0 \\
\hline $\begin{array}{l}\text { Department of Psychiatry, Wuhan Mental Health Center, } \\
\text { Wuhan, Hubei Province, China }\end{array}$ & Zhong BL & 2020 & Cross sectional survey & 6,910 \\
\hline $\begin{array}{l}\text { Unit of Psychiatry, Institute of Translational Medicine, Faculty of } \\
\text { Health Sciences, University of Macau, Macao SAR, China }\end{array}$ & Xiang YT & 2020 & Research paper & 0 \\
\hline $\begin{array}{l}\text { Unit of Psychiatry, Institute of Translational Medicine, Faculty } \\
\text { of Health Sciences, University of Macau, Macao SAR, China }\end{array}$ & Xiang YT & 2020 & Review & 0 \\
\hline $\begin{array}{l}\text { Unit of Psychiatry, Institute of Translational Medicine, Faculty of } \\
\text { Health Sciences, University of Macau, Macao SAR, China }\end{array}$ & Li W & 2019 & Review & 0 \\
\hline $\begin{array}{l}\text { Department of Psychiatry, First Affiliated Hospital, Zhejiang } \\
\text { University School of Medicine, Hangzhou, China }\end{array}$ & Lai J & 2020 & Cross-sectional study & 1,257 \\
\hline $\begin{array}{l}\text { Center for Quantitative Health and Department of Psychiatry, } \\
\text { Massachusetts General Hospital, Boston }\end{array}$ & Perlis RH & 2020 & Invited Commentary & 0 \\
\hline $\begin{array}{l}\text { Department of Educational Psychology, Counseling, and Special } \\
\text { Education, The Pennsylvania State University, University Park, } \\
\text { PA 16802, USA }\end{array}$ & Zhai Y & 2020 & Correspondence & 0 \\
\hline Harvard TH Chan School of Public Health, Boston, MA, USA & Yao $\mathrm{H}$ & 2020 & Correspondence & 0 \\
\hline $\begin{array}{l}\text { Department of Psychiatry, the First Affiliated Hospital of China } \\
\text { Medical University, Shenyang 110001, China }\end{array}$ & Duan L & 2020 & Comment & 0 \\
\hline
\end{tabular}


Table 5. Articles related with other's countries experience

\begin{tabular}{|c|c|c|c|c|}
\hline Region of university & Author & Year of publication & Type of paper & Sample size \\
\hline $\begin{array}{l}\text { Department of Neuroscience, Section of Psychiatry, } \\
\text { Università Cattolica del Sacro Cuore, Rome, Italy }\end{array}$ & Sani G & 2020 & Letter to the Editor & 0 \\
\hline Boston, USA & Freeman MP & 2020 & Editorial & 0 \\
\hline $\begin{array}{l}\text { Department of Psychiatry, School of Medicine, National Defense } \\
\text { Medical College, Tokorozawa, Japan }\end{array}$ & Shigemura J & 2019 & Letter to the Editor & 0 \\
\hline
\end{tabular}

Table 6. Publication on mental health of health care workers

\begin{tabular}{|c|c|c|c|c|}
\hline Region of university & Author & Year of publication & Type of paper & Sample size \\
\hline Department of Child \& Adolescent Psychiatry, SMMS, UCD, Ireland & Gavin B & 2020 & Letter & 0 \\
\hline $\begin{array}{l}\text { Department of Psychiatry, Trinity College Dublin, } \\
\text { St. Patrick's University Hospital, James Street, Dublin 8, Ireland }\end{array}$ & Colbert SA & 2020 & Comment & 0 \\
\hline $\begin{array}{l}\text { King's Centre for Military Health Research, Institute of Psychology, } \\
\text { Psychiatry and Neuroscience, King's College London, } \\
10 \text { Cutcombe Road, London, UK }\end{array}$ & Williamson V & 2020 & Comment & 0 \\
\hline $\begin{array}{l}\text { Department of Psychiatry, Pamela Youde Nethersole Eastern } \\
\text { Hospital, Hong Kong }\end{array}$ & Chung JPY & 2020 & Letter ot the editor & 0 \\
\hline $\begin{array}{l}\text { Department of Mental Health and Drug Abuse, AUSL Modena, } \\
\text { Modena, Italy }\end{array}$ & Starace F & 2020 & Editorial & 0 \\
\hline $\begin{array}{l}\text { Clinical Nursing Teaching and Research Section, The Second } \\
\text { Xiangya Hospital, Central South University, Changsha 410011, } \\
\text { China; Mental Health Institute, The Second Xiangya Hospital, } \\
\text { Central South University, Changsha 410011, China }\end{array}$ & Chen Q & 2020 & Letter & 0 \\
\hline
\end{tabular}

with mental illness, disability, and chronic conditions). At the same time, it is necessary to reduce the spread of the COVID-19 disease within the outpatient and inpatient services affiliated with Mental Health Departments. ${ }^{51}$ Facing this large scale infectious public health event, medical staff are under both physical and psychological pressure. Staff worried about the shortage of protective equipment and feelings of incapability when faced with critically ill patients. Many staff mentioned that they did not need a psychologist, but needed more rest without interruption and enough protective supplies. Finally, they suggested training on psychological skills to deal with patients' anxiety, panic, and other emotional problems and, if possible, for mental health staff to be on hand to directly help these patients (Table 6). ${ }^{52}$

\section{Telemedicine and psychological support during pandemia}

Undeniably this is the first pandemic of the digital age and research of social media rumours during crisis events highlights the importance of the release of substantive updates at regular intervals from trusted sources. False information tends to proliferate in the absence of updates from official channels. The COVID-19 pandemic has occurred at a time when the human race is more connected than ever. While physical connectivity, by way of widespread travel, has accelerated the spread of the disease around the planet, electronic connectivity provides a tool that, if utilized responsibly, can mitigate its effects. ${ }^{53}$ An unexpected obstacle of the COVID-19 epidemic is that the university public hospitals have had to take unprecedented measures of containment, including asking non-essential medical staff to stay at home. In fact, medical students practicing in the surgical departments find themselves idle, as non-urgent surgical activity has been canceled, until further notice. Blended-learning, defined as the combination of conventional face-to-face learning and asynchronous or synchronous e-learning, have grown quickly and are now extensively used in medical education. ${ }^{54}$ While the epidemic is active and clinical research continues there is no question that clinical researchers are having to make tough decisions about ongoing clinical trials due to the widespread COVID-19 pandemic. Although some guidance has been offered from local and national organizations, it is still ultimately the responsibility of the principal investigation (PI) to evaluate the risk-benefit ratio of ongoing research. When making research decisions, PIs should consider all factors that affect the risk-benefit ratio of continuing research 
during this time. ${ }^{55}$ In Paris in s psychiatry department although psychiatrists and psychologists were rather reluctant to embrace telepsychiatry before this crisis, the pandemic has required a shift of $90 \%$ of our outpatient activity and liaison psychiatry to telepsychiatry. The good news is that this quick shift is well accepted by patients, psychiatrists, and psychologists. To address the mental health issues of the medical and nonmedical hospital staff exposed to overwork, stress, difficult ethical decisions, and multiple deaths, along with confinement and the fear of contamination for themselves and their families, we have proposed a dedicated hotline for psychiatry teleconsultation, which has been positively received. ${ }^{56}$ In Italy in a psychiatric department switched almost all of the outpatients visits to telemedicine sessions. They had very little, if any, experience with telemedicine, but they had no other choice. For most patients, they just used the phone. In their unit instituted a policy in October 2019 that banned handshakes, in order to prevent hospital infections. Each room on their units has a sign inviting everyone to greet one another with a smile instead of shaking hands. They knew that washing hands and avoiding handshakes were necessary, but not sufficient, measures. Indeed, they saw quickly that many people who carefully washed their hands and did not touch anyone or anything became infected regardless. ${ }^{57} \mathrm{Re}-$ garding delivering services only via telephone, telemedicine, or other technologies. Most clinicians have not used telemedicine as a routine part of their daily work. Among the resources that can help clinicians learn about telemedicine, "BestPracticesinVideoconferencingBasedTelementalHealth" (https://www.psychiatry.org/File\%20Library/Psychiatrists/ Practice/Telepsychiatry/APA-ATABest-Practices-in-Videoconferencing-Based-Telemental-Health.pdf), a consensus guideline from the American Psychiatric Association and the American Telemedicine. ${ }^{58}$ The COVID-19 crisis and global pandemic may be the defining moment for digital mental health, but what that definition will be remains unknown. Ensuring the right use of telehealth and app tools today in this crisis and investment in people and training to support them tomorrow during the potential mental health fallout of the current crisis as well as readiness for tomorrow can cement the future of digital mental health as simply mental health. Bending the curve in the right direction will require funding, research, policy changes, training, and equity, but these investments will continue to yield higher returns at every step. ${ }^{59}$ "Action at a distance" may be the new model for clinical researchers in the context of the COVID-19 pandemic, which may require social distancing for the next 18 months. Therapists must minimize face-to-face contact with vulnerable populations. But they must also persist, adapt, and help older patients and study participants during the pandemic. Guidance for reduce effects of social isolation on older adults engaged in clinical research the use of clinical research platforms to connect with older adults and chronicle the evolution of this unprecedented public health event. ${ }^{60}$ In the COVID-19 epidemic, a new psychological crisis intervention model was developed through internet technology use. This new model from the West China Hospital integrates physicians, psychiatrists, psychologists, and social workers into Internet platforms to carry out psychological intervention to patients, their families, and medical staff. The central idea is to join Internet technology and the whole intervention process, as well as to combine early intervention with later rehabilitation. It is noteworthy that despite the common mental health problems and disorders found among patients and health workers in such settings, most health professionals working in isolation units and hospitals do not receive any training for providing mental health care. ${ }^{61}$ In order to solve some of the psychological and mental problems that quarantine may bring, a new type of psychological and mental problem intervention strategy that is feasible and accessible is urgently needed. In addition to the face-to-face routine psychological counseling mode, remote written counseling may become a new type of psychological counseling mode in the context of public health emergencies. Structured letter therapy is a kind of feasible psychological intervention approach. Structured letter therapy should have the following characteristics: Includes Patient Page, Intervention Page, and Continuation Page. ${ }^{2}$ Online psychological self-help intervention systems, including online cognitive behavioral therapy for depression, anxiety, and insomnia (e.g., on WeChat), have also been developed. In addition, several artificial intelligence (AI) programmes have been put in use as interventions for psychological crises during the epidemic. In general, online mental health services being used for the COVID-19 epidemic are facilitating the development of Chinese public emergency interventions, and eventually could improve the quality and effectiveness of emergency interventions. ${ }^{63}$ The psychological assistance hotline teams composed of volunteers who have received psychological assistance training in dealing with the 2019-nCoV epidemic provide telephone guidance to help deal with mental health problems. Hundreds of medical workers are receiving these interventions, with good response, and their provision is expanding to more people and hospitals. Understanding the mental health response after a public health emergency might help medical workers and communities prepare for a population's response to a disaster. ${ }^{64}$ Many of the research papers about COVID-19 in international journals were written by researchers in China, which led to great concerns because these findings cannot directly benefit frontline health profes- 
sionals and policy makers because of the language barrier. It is critical for health science to be published in English-language journals to facilitate communication and enable global coordination and timely epidemic response. However, some media were concerned that Chinese researchers within academic organizations concentrated on publishing papers in prestigious international journals but paid inadequate attention to epidemic prevention of COVID-19 and neglected to disseminate their findings within Chinese-language journals (Table 7). ${ }^{65}$

\section{Pandemia and social psychiatry}

With the advent of the COVID-19 pandemic, stigma and xenophobia have become major elements of the public discourse and a regrettable, but everyday reality. We have been witnessing increased antagonism toward specific groups with high infection rate that in turn has led to patients presenting with both enacted and felt stigma and associated increased anxiety and depression. Combining the stigma associated with mental illness with the stigma now shown toward certain COVID-positive patients may lead to double stigma, a barrier to psychiatric treatment adherence with resultant increased morbidity. Reducing stigma requires both national and international interventions. To successfully address all these challenges and research themes in a manner that acknowledges the truly global nature and impact of the crisis we are witnessing, we see an urgent need for collaboration and consensus guidelines from psychiatric organizations and their members (task forces, treatment and education guidelines, multi-site /multicountry research, etc.). ${ }^{66}$ In response to the COVID-19 pandemic, Jails pose a unique set of challenges to COVID-19 prevention, detection, and management mitigation that deserves

Table 7. Publications on telemedicine

\begin{tabular}{|c|c|c|c|c|}
\hline Region of university & Author & Year of publication & Type of paper & Sample size \\
\hline $\mathrm{CHI}$ at Crumlin, Crumlin, Dublin 12, Ireland & O’Brien M & 2020 & Letter & 0 \\
\hline $\begin{array}{l}\text { Department of Digestive Surgery, Louis-Mourier Hospital, DMU } \\
\text { ESPRIT, GHU AP-HP, Nord, University of Paris, Paris, France }\end{array}$ & Moszkowicz D & 2020 & Viewpoint & 0 \\
\hline $\begin{array}{l}\text { Geriatric Research Education and Clinical Center, Eugene J Towbin } \\
\text { Healthcare Center, Central Arkansas Veterans Healthcare System, } \\
\text { North Little Rock, AR, United States }\end{array}$ & Padala PR & 2020 & Comment & 0 \\
\hline $\begin{array}{l}\text { Hôpital Bicêtre, } 78 \text { rue du Général Leclerc, Le Kremlin-Bicêtre, } \\
\text { 94270, France }\end{array}$ & Corruble E & 2020 & Commentary & 0 \\
\hline University of Siena School of Medicine, Siena, Tuscany, Italy & Fagiolini A & 2020 & Commentary & 0 \\
\hline University of Louisville Depression Center, Louisville, Kentucky, USA & Wright JH & 2020 & Editorial & 0 \\
\hline $\begin{array}{l}\text { Division of Digital Psychiatry, Beth Israel Deaconess Medical Center, } \\
\text { Harvard Medical School, Boston, MA, United States }\end{array}$ & Torous J & 2020 & Article & 0 \\
\hline $\begin{array}{l}\text { Department of Psychiatry, Washington University School of } \\
\text { Medicine, St. Louis, Missouri, USA }\end{array}$ & Nicol GE & 2020 & Brief Report & 0 \\
\hline $\begin{array}{l}\text { PostGraduate Program in Health Sciences, School of Medicine of } \\
\text { ABC, Santo André, São Paulo, Brazil }\end{array}$ & Lima CKT & 2020 & Letter to the Editor & 0 \\
\hline $\begin{array}{l}\text { The National Clinical Research Center for Mental Disorder } \\
\text { \& Beijing Key Laboratory of Mental Disorders, Beijing } \\
\text { Anding Hospital, Capital Medical University, Beijing, China }\end{array}$ & Xiao C & 2020 & Correspondence & 0 \\
\hline $\begin{array}{l}\text { Department of Psychiatry, Nanfang Hospital, Southern Medical } \\
\text { University, Guangzhou 510515, China; Guangdong-Hong Kong- } \\
\text { Macao Greater Bay Area Center for Brain Science and Brain- } \\
\text { Inspired Intelligence, Southern Medical University, Guangzhou, } \\
\text { China; The Third People’s Hospital of Qinghai Province, } \\
\text { Xining, China }\end{array}$ & Liu S & 2020 & Correspondence & 0 \\
\hline $\begin{array}{l}\text { Department of Psychiatry, RenMin Hospital of Wuhan } \\
\text { University, Wuhan 430060, China }\end{array}$ & Kang L & 2020 & Correspondence & 0 \\
\hline $\begin{array}{l}\text { Unit of Psychiatry, Institute of Translational Medicine, Faculty of } \\
\text { Health Sciences, University of Macau 999078, Macau SAR, } \\
\text { China; Center for Cognition and Brain Sciences, University of } \\
\text { Macau, Macao SAR, China }\end{array}$ & Xiang YT & 2020 & Correspondence & 0 \\
\hline
\end{tabular}


immediate attention. Social distancing to reduce the rate of disease transmission is not feasible in jails, where people are confined to small living spaces and institutions are often overcapacity. Hand-washing can be undermined by policies limiting soap access or requiring individual purchase of soap. Many jails restrict access to hand sanitizer, which contains alcohol, fearing individuals will ingest it. Along with structural barriers to disease prevention, there are administrative challenges that impede timely access to healthcare professionals when sick. This is especially concerning because jails have a high proportion of people with underlying health conditions, making them more susceptible to severe COVID-19 infection. ${ }^{67}$ It is probable that coronavirus disease (COVID-19) will be transmitted to people experiencing homelessness, which will become a major problem in particular in North America. If cities impose a lockdown to prevent COVID-19 transmission, there are few emergency preparedness plans to transport and provide shelter for the large number of people experiencing homelessness. In lockdowns, public spaces are closed, movement outside homes are restricted, and major roads of transport might be closed, all of which might negatively affect people experiencing homelessness. It is unclear how and where unsheltered people experiencing homelessness will be moved to if quarantines and lockdowns are implemented. ${ }^{68}$ Sub standard implementation of appropriate infection prevention and control measures could influence COVID-19 global spread. These include early recognition, source control and additional precautions at point-of-care for persons under investigation or with confirmed COVID-19. The myriad factors influencing the COVID-19 pandemic are not unique. High population density, unsanitary conditions and aninade-quate health care infrastructure were also at the core of the Zika epidemic. As with any infectious disease emergency, public health officials need also to address the epidemic of fear. In appropriate prevention and treatment strategies such as herbal remedies and exaggerated numbers of persons affected by COVID-19 cases have circulated on social media. The COVID-19 pandemic, rapid spread and magnitude unleashed panic and episodes of racism against people of Asian descent. ${ }^{69}$ Trust encourages social interactions and cooperation among health professionals. Trust has been shown to help improve retention, motivation, performance and quality of care. One way to promote trust among organizations and health professionals is through the frequent provision of information. A medical officer in Beijing, who had experienced SARS, proposed that regular and timely provision of information was useful in alleviating anxiety to some degree. Additionally, frequent communication with and encouragement to health workers from governors and employers leads to them feeling protected. If a health professional does become infected, compensation may also be an- other incentive to work. It is important to provide physical protective material. However, psychological support should also be made available. Trust may also be a key element. ${ }^{70}$ Of the 150 million international migrant workers (IMWs) worldwide, $95 \%$ reside in the five WHO regions in which cases of coronavirus disease 2019 (COVID-19) have been confirmed. The absence of a coordinated response for IMWs highlights a key deficiency in public health planning. During the epidemic, IMWs should be provided more accessible health care. Public health campaigns should be available in multiple languages and diffused through various communication channels and networks of IMWs as soon as possible. In addition, more countries should ratify the International Convention on the Protection of the Rights of All Migrant Workers and Members of Their Families to provide global health equity and ensure that migrant workers' health is not neglected in future epidemics and disasters (Table 8). ${ }^{71}$

\section{DISCUSSION}

Assessing and analyzing the overall content of the publications there is a greater need for research paper which will explore with greater scientific approach the psychiatric factors and consequences of this sudden and terrible pandemia. The COVID-19 pandemic will create unprecedented health and social challenges globally. People with serious mental illnesses will be at uniquely high risk during this period, as will be the public mental health care system central to delivering their care. Constructive peer-support, supportive therapy and early mental health interventions will improve their quality of care, both for themselves and the patients. It is also important for us to stay away from misinformation ourselves and be responsible for what we share on media platforms. It is imperative to remember that mass mayhem and panic due to uncertainty of an illness can cause more damage than the virus itself. With the scare of COVID-19 pandemic on the rise, it is time that as psychiatrists will try to incorporate the healthcare services keeping mental health at the epicenter. Early identification of distress and timely psychological interventions can, not only prevent crisis at times of pandemics but also help in containing its extend. The specific response to the mental distress of children who are quarantined should also be considered when designing psychological intervention strategies in response to COVID-19. Vigilance about the health of the elderly in long-term care is essential not only for their health but also to protect the health care system from being overwhelmed by severe COVID-19 cases. The information from media and social network should be closely controlled and community supportive psychological interventions globally promoted. Psychological support for those in 
Table 8. Publications related with social psychiatry

\begin{tabular}{|c|c|c|c|c|}
\hline Region of university & Author & $\begin{array}{c}\text { Year of } \\
\text { publication }\end{array}$ & Type of paper & $\begin{array}{l}\text { Sample } \\
\text { size }\end{array}$ \\
\hline $\begin{array}{l}\text { Departments of Psychiatry, Neurology, and Anesthesiology, Rutgers Robert Wood } \\
\text { Johnson Medical School, USA; and Department of Psychological Medicine, } \\
\text { Institute of Psychiatry, Psychology \& Neuroscience, King's College London, UK }\end{array}$ & Kaufman KR & 2020 & Editorial & 0 \\
\hline $\begin{array}{l}\text { Tufts Medical Center, Department of Medicine, Division of Geographic Medicine } \\
\text { and Infectious Diseases, Boston MA }\end{array}$ & Wurcel AG & 2020 & Correspondence & 0 \\
\hline $\begin{array}{l}\text { School of Public Health, University of Texas Health Science Center at Houston, } \\
\text { Houston, TX 78229, USA; National Center on Homelessness Among Veterans, } \\
\text { US Department of Veterans Affairs, Tampa, FL, USA; Department of Psychiatry, } \\
\text { Yale University School of Medicine, Yale University, New Haven, CT, USA }\end{array}$ & Tsai J & 2020 & Comment & 0 \\
\hline $\begin{array}{l}\text { Department of Psychiatry, Faculty of Medicine, University of Toronto, Toronto, } \\
\text { ON, Canada }\end{array}$ & Malta M & 2020 & Commentary & 0 \\
\hline $\begin{array}{l}\text { Health Promotion and Human Behavior, Graduate School of Medicine/ } \\
\text { School of Public Health, Kyoto University, Kyoto, Japan }\end{array}$ & Imai $\mathrm{H}$ & 2020 & $\begin{array}{l}\text { Letter to the } \\
\text { Editor }\end{array}$ & 0 \\
\hline $\begin{array}{l}\text { Global and Community Mental Health Research Group, Department of Psychology, } \\
\text { University of Macau, Macau Special Administrative Region 999078, China }\end{array}$ & Liem A & 2020 & Correspondence & 0 \\
\hline
\end{tabular}

front-line roles and affected by the COVID-19 should be prioritized and made more readily accessible.

\section{Conflicts of Interest}

The authors have no potential conflicts of interest to disclose.

\section{Author Contributions}

Conceptualization: Konstantinos Kontoangelos. Data curation: Marina Economou. Formal analysis: Marina Economou. Investigation: Konstantinos Kontoangelos. Methodology: Marina Economou. Project administration: Marina Economou. Resources: Marina Economou. Software: Konstantinos Kontoangelos. Supervision: Charalambos Papageorgiou. Validation: Charalambos Papageorgiou. Visualization: Konstantinos Kontoangelos. Writingoriginal draft: Konstantinos Kontoangelos. Writing_review \& editing: Konstantinos Kontoangelos.

\section{ORCID iDs}

Konstantinos Kontoangelos

Marina Economou

Charalambos Papageorgiou

https://orcid.org/0000-0001-7746-3909 https://orcid.org/0000-0002-6742-4348 https://orcid.org/0000-0001-7635-1956

\section{REFERENCES}

1. WHO. Coronavirus disease (COVID-19) pandemic. WHO emergencies (Internet). Geneva, Switherzland. Updated 6 Mar 2020. Available at: https://www.who.int/emergencies/diseases/novel-coronavirus-2019/situation-reports.

2. WHO. Coronavirus disease 2019 (COVID-19) Situation Report-70 (Internet) Geneva, Switherland. Updated 19-30 March 2020. https:// www.who.int/publications-detail/covid-19-operational-guidance-formaintaining-essential-health-services-during-an-outbreak.

3. Fiorillo A, Gorwood P. The consequences of the COVID-19 pandemic on mental health and implications for clinical practice. Eur Psychiatry 2020;63:e32.

4. Xiang YT, Yang Y, Li W, Zhang L, Zhang Q, Cheung T,et al. Timely mental health care for the 2019 novel coronavirus outbreak is urgently needed. Lancet Psychiatry 2020;7:228-229.

5. Druss BG. Addressing the COVID-19 pandemic in populations with serious mental illness. JAMA Psychiatry 2020 [Epub Ahead of Print].
6. Banerjee D. The COVID-19 outbreak: cucial role the psychiatrists can play. Asian J Psychiatr 2020;50:102014.

7. Torales J, O'Higgins M, Castaldelli-Maia JM, Ventriglio A. The outbreak of COVID-19 coronavirus and its impact on global mental health. Int J Soc Psychiatry 2020 [Epub Ahead of Print].

8. Gardner W, States D, Bagley N. The Coronavirus and the risks to the elderly in long-term care. J Aging Soc Policy 2020;3:1-6.

9. Cohen SP, Baber ZB, Buvanendran A, McLean LTCBC, Chen Y, Hooten WM, et al. Pain management best practices from multispecialty organizations during the COVID-19 pandemic and public health crises. Pain Med 2020 [Epub ahead of print].

10. Zhang K, Zhou X, Liu H, Hashimoto K. Treatment concerns for psychiatric symptoms in COVID-19-infected patients with or without psychiatric disorders. Br J Psychiatry 2020 [Epub ahead of print].

11. Siskind D, Honer WG, Clark S, Correll CU, Hasan A, Howes O, et al. Consensus statement on the use of clozapine during the COVID-19 pandemic. J Psychiatry Neurosci 2020;45:222-223.

12. Arden MA, Chilcot J .Health psychology and the coronavirus (COVID-19) global pandemic: a call for research. Br J Health Psychol 2020; 25:231-232.

13. Cullen W, Gulati G, Kelly BD. Mental health in the Covid-19 pandemic. QJM 2020;113:311-312.

14. Bo HX, Li W, Yang Y, Wang Y, Zhang Q, Cheung T, et al. Posttraumatic stress symptoms and attitude toward crisis mental health services among clinically stable patients with COVID-19 in China. Psychol Med 2020;27:1-7.

15. Monson E, Caron J, McCloskey K, Brunet A. Longitudinal analysis of quality of life across the trauma spectrum. Psychol Trauma 2017;9: 605-612.

16. Asmundson GJG, Taylor S. How health anxiety influences responses to viral outbreaks like COVID-19: what all decision-makers, health authorities, and health care professionals need to know. J Anxiety Disord 2020;71:102211.

17. Asmundson GJG, Taylor S. Coronaphobia: fear and the 2019-nCov outbreak. J Anxiety Disord 2020;70:102196.

18. Barati M, Bashirian S, Jenabi E, Khazaei S, Karimi-Shahanjarini A, Zareian $\mathrm{S}$ et al. Factors associated with preventive behaviours of COVID-19 among hospital staff in Iran 2020: an application of the protection motivation theory. J Hosp Infect 2020 [Epub ahed of print]. 
19. Ahmad A, Mueller C, Tsamakis K. COVID-19 pandemic: a public and global mental health opportunity for social transformation? BMJ 2020;369:m1383.

20. Wang H, Li T, Barbarino P, Gauthier S, Brodaty H, Molinuevo JL, et al. Dementia care during COVID-19.Lancet 2020;395:1190-1191.

21. Yang Y, Li W, Zhang Q, Zhang L, Cheung T, Xiang YT. Mental health services for older adults in China during the COVID-19 outbreak. Lancet Psychiatry 2020;7:e19.

22. Liu JJ, Bao Y, Huang X, Shi J, Lu L. Mental health considerations for children quarantined because of COVID-19. Lancet Child Adolesc Health 2020;4:347-349.

23. Dalton L, Rapa E, Stein A. Protecting the psychological health of children through effective communication about COVID-19. Lancet Child Adolesc Health 2020;4:346-347.

24. Narzisi A. Handle the autism spectrum condition during coronavirus (COVID-19) stay at home period: ten tips for helping parents and caregivers of young children. Brain Sci 2020;10:207.

25. Cluver L, Lachman JM, Sherr L, Wessels I, Krug E, Rakotomalala S, et al. Parenting in a time of COVID-19. Lancet 2020;395:e64.

26. Asmundson GJG, Taylor S. Coronaphobia: fear and the 2019-nCoV outbreak. J Anxiety Disord 2020;70:102196.

27. Ornell F, Schuch JB, Sordi AO, Kessler FHP. "Pandemic fear" and COVID19: mental health burden and strategies. Braz J Psychiatry 2020; 42:232-235.

28. Yao H, Chen JH, Xu YF. Rethinking online mental health services in China during the COVID-19 epidemic. Asian J Psychiatr 2020;50: 102015.

29. Xiang YT, Yu X, Sartorius N, Ungvari GS, Chiu HF. Mental health in China: challenges and progress. Lancet 2012; 380: 1715-1716.

30. Huang J, Liu F, Teng Z, Chen J, Zhao J, Wang X, et al. Care for the psychological status of frontline medical staff fighting against COVID-19. Clin Infect Dis 2020 [Epub ahead of print].

31. Kang L, Ma S, Chen M, Yang J, Wang Y, Li R, et al. Impact on mental health and perceptions of psychological care among medical and nursing staff in Wuhan during the 2019 novel coronavirus disease outbreak: a cross-sectional study. Brain Behav Immun 2020 [Epub ahead of print].

32. Liu N, Zhang F, Wei C, Jia Y, Shang Z, Sun L, et al. Prevalence and predictors of PTSS during COVID-19 outbreak in China hardest-hit areas: Gender differences matter. Psychiatry Res 2020;287:112921.

33. Cui LB, Wang XH, Wang HN. Challenges facing coronavirus disease 2019: Psychiatric services for patients with mental disorders. Psychiatry Clin Neurosci 2020 [Epub ahead of print].

34. Zhang J, Lu H, Zeng H, Zhang S, Du Q, Jiang T, Du B. The differential psychological distress of populations affected by the COVID-19 pandemic. Brain Behav Immun 2020 [Epub ahead of print].

35. Zhong BL, Luo W, Li HM, Zhang QQ, Liu XG, Li WT et al. Knowledge, attitudes, and practices towards COVID-19 among Chinese residents during the rapid rise period of the COVID-19 outbreak: a quick online cross-sectional survey. Int J Biol Sci 2020;16:1745-1752.

36. Xiang YT, Zhao YJ, Liu ZH, Li XH, Zhao N, Cheung T, et al. The COVID-19 outbreak and psychiatric hospitals in China: managing challenges through mental health service reform. Int J Biol Sci 2020;16:1741-1744.

37. Xiang YT, Jin Y, Wang Y, Zhang Q, Zhang L, Cheung T. Tribute to health workers in China: a group of respectable population during the outbreak of the COVID-19. Int J Biol Sci 2020;16:1739-1740.

38. Li W, Yang Y, Liu ZH, Zhao YJ, Zhang Q, Zhang L, et al. Progression of Mental Health Services during the COVID-19 Outbreak in China. Int J Biol Sci 2020;16:1732-1738.

39. Lai J, Ma S, Wang Y, Cai Z, Hu J, Wei N et al. Factors associated with mental health outcomes among health care workers exposed to coronavirus disease 2019. JAMA Netw Open 2020;3:e203976.

40. Perlis RH. Exercising heart and head in managing coronavirus disease 2019 in Wuhan. JAMA Netw Open 2020;3:e204006.

41. Zhai Y, Du X. Mental health care for international Chinese students affected by the COVID-19 outbreak. Lancet Psychiatry 2020;7:e22.
42. Yao H, Chen JH, Xu YF. Patients with mental health disorders in the COVID-19 epidemic. Lancet Psychiatry 2020;7:e21.

43. Duan L, Zhu G. Psychological interventions for people affected by the COVID-19 epidemic. Lancet Psychiatry 2020;7:300-302.

44. Sani G, Janiri D, Di Nicola M, Janiri L, Ferretti S, Chieffo D. Mental health during and after the COVID-19 emergency in Italy. Psychiatry Clin Neurosci 2020 [Epub ahead of print].

45. Freeman MP. COVID-19 from a psychiatry perspective: meeting the challenges. J Clin Psychiatry 2020;81:20ed13358.

46. Shigemura J, Ursano RJ, Morganstein JC, Kurosawa M, Benedek DM. Public responses to the novel 2019 coronavirus (2019-nCoV) in Japan: mental health consequences and target populations. Psychiatry Clin Neurosci 2020;74:281-282.

47. Gavin B, Hayden J, Adamis D, McNicholas F. Caring for the psychological well- being of healthcare professionals in the Covid-19 pandemic crisis. Ir Med J 2020;113:51.

48. Colbert SA, McCarron S, Ryan G, McLoughlin DM. Images in clilical ECT: immediate impact of COVID-19 on ECT practice. J ECT 2020 [Epub ahead of print].

49. Williamson V, Murphy D, Greenberg N. COVID-19 and experiences of moral injury in front-line key workers. Occup Med (Lond) [Epub ahead of print].

50. Chung JPY, Yeung WS. Staff Mental Health Self-Assessment During the COVID-19 Outbreak. East Asian Arch Psychiatry 2020;30:34.

51. Starace F, Ferrara M. COVID19 disease emergency operational instructions for Mental health Departments issued by the Italian Society of Epidemiological Psychiatry. Epidemiol Psychiatr Sci 2020;29:e116.

52. Chen Q, Liang M, Li Y, Guo J, Fei D, Wang L, et al. Mental health care for medical staff in China during the COVID-19 outbreak. Lancet Psychiatry 2020;7:e15-e16.

53. O'Brien M, Moore K, McNicholas F. Social media spread during Covid-19: the pros and cons of likes and shares. Ir Med J 2020;113:52.

54. Moszkowicz D, Duboc H, Dubertret C, Roux D, Bretagnol F. Daily medical education for confined students during COVID-19 pandemic: a simple videoconference solution. Clin Anat 2020 [Epub ahead of print].

55. Padala PR, Jendro AM, Padala KP. Conducting clinical research during the COVID-19 pandemic: investigator and participant perspectives. JMIR Public Health Surveill 2020;6:e18887.

56. Corruble E. A viewpoint from Paris on the COVID-19 pandemic: a necessary turn to telepsychiatry. J Clin Psychiatry 2020;81:20com13361.

57. Fagiolini A, Cuomo A, Frank E. COVID-19 diary from a psychiatry department in Italy. J Clin Psychiatry 2020 ;81:20com13357.

58. Wright JH, Caudill R. Remote treatment delivery in response to the COVID- 19 pandemic. Psychother Psychosom 2020;89:1-3.

59. Torous J, Jän Myrick K, Rauseo-Ricupero N, Firth J. Digital mental health and COVID-19: using technology today to accelerate the curve on access and quality tomorrow. JMIR Ment Health 2020;7:e18848.

60. Nicol GE, Piccirillo JF, Mulsant BH, Lenze EJ. Action at a distance: geriatric research during a pandemic. J Am Geriatr Soc 2020;68:922-925.

61. Lima CKT, Carvalho PMM, Lima IAAS, Nunes JVAO, Saraiva JS, de Souza RI, et al. The emotional impact of Coronavirus 2019-nCoV (new Coronavirus disease). Psychiatry Res 2020;287:112915.

62. Xiao C. A novel approach of consultation on 2019 novel coronavirus (COVID-19)-related psychological and mental problems: structured letter therapy. Psychiatry Investig 2020;17:175-176.

63. Liu S, Yang L, Zhang C, Xiang YT, Liu Z, Hu S, et al. Online mental health services in China during the COVID-19 outbreak. Lancet Psychiatry 2020;7:e17-e18.

64. Kang L, Li Y, Hu S, Chen M, Yang C, Yang BX, et al. The mental health of medical workers in Wuhan, China dealing with the 2019 novel coronavirus. Lancet Psychiatry 2020;7:e14.

65. Xiang YT, Li W, Zhang Q, Jin Y, Rao WW, Zeng LN, et al. Timely research papers about COVID-19 in China. Lancet 2020;395:684-685.

66. Kaufman KR, Petkova E, Bhui KS, Schulze TG. A global needs assess- 
ment in times of a global crisis: world psychiatry response to the COVID-19 pandemic. BJPsych Open 2020;6:e48.

67. Wurcel AG, Dauria E, Zaller N, Nijhawan A, Beckwith C, Nowotny K, et al. Spotlight on jails: COVID-19 mitigation policies needed now. Clin Infect Dis 2020 [Epub ahead of print].

68. Tsai J, Wilson M. COVID-19: a potential public health problem for homeless populations. Lancet Public Health 2020;5:e186-e187.

69. Malta M, Rimoin AW, Strathdee SA. The coronavirus 2019-nCoV epi- demic: Is hindsight 20/20? EClinicalMedicine 2020;20:100289.

70. Imai $\mathrm{H}$. Trust is a key factor in the willingness of health professionals to work during the COVID-19 outbreak: experience from the H1N1 pandemic in Japan 2009. Psychiatry Clin Neurosci 2020;74:329-330.

71. Liem A, Wang C, Wariyanti Y, Latkin CA, Hall BJ . The neglected health of international migrant workers in the COVID-19 epidemic. Lancet Psychiatry 2020;7:e20. 